\title{
Financial Development, Credit, and Business Cycles*
}

\author{
Tiago Pinheiro \\ City University London \\ Francisco Rivadeneyra \\ Bank of Canada \\ Marc Teignier \\ University of Barcelona
}

July 18, 2016

\begin{abstract}
How does financial development affect the magnitude of the business cycles fluctuations? We examine this question in a general equilibrium model with heterogeneous agents and endogenous credit constraints based on Kiyotaki (1998). We show that there is a hump-shaped relationship between the degree of financial frictions and the amplification of unexpected productivity shocks. This non-monotonic relation is due to the fall in financial frictions having two opposite effects on the response of output. One effect is the reallocation of productive inputs between agent types, which, while active, increases with the fall in financial frictions. The other effect is the change in the demand of inputs, which decreases with the fall in financial frictions. At low levels of financial development the reallocation effect dominates and a fall in financial frictions increases the amplification of productivity shocks. In contrast, at higher levels of financial development, a fall in financial frictions decreases the shock amplification because the reallocation effect disappears while the effect on the demand of inputs is still present.
\end{abstract}

JEL classification numbers: E32, E60.

Keywords: financial intermediation, borrowing constraints, shock amplification.

*TIAGO PINHEIRO is a visiting lecturer at Cass Business School of City University of London (E-mail: tiago.pinheiro@city.ac.uk), FRANCISCO RIVADENEYRA is an Assistant Director of Research at the Bank of Canada (riva@bankofcanada.ca), MARC TEIGNIER is an assistant professor at the Economics department of the University of Barcelona (E-mail: marc.teignier@ub.edu). We thank the comments of the editor, Pok-sang Lam and an anonymous referee. This article was developed while Tiago Pinheiro was at the Norwegian School of Economics. Teignier acknowledges financial support from Spanish Ministry of Economy and Competitiveness, Grant ECO2012-36719, and from Generalitat of Catalonia, Grant SGR2014-493. All remaining errors are ours. The views presented here do not necessarily reflect the ones of the Bank of Canada. 


\section{Introduction}

In the presence of borrowing constraints, the financial sector amplifies business cycle fluctuations in excess of the purely technological volatility. In this paper, we ask whether a more developed financial sector leads to more or less amplification. We show that in an economy with heterogenous agents and endogenous borrowing constraints, the degree of financial development has two opposite effects, which generate a hump-shaped relationship between financial development and the response of output to an unexpected productivity shock.

Our starting point is the model of endogenous borrowing constraints of Kiyotaki (1998), where agents are heterogenous in their ability and production requires a durable and an intermediate input. We modify the credit constraint by adding a financial efficiency parameter - the level of financial development - to capture cross-country differences in institutional quality and in financial innovation. We show that, depending on the value of this financial efficiency parameter, the equilibrium can be one of three types. First, for low values of the parameter, the well-known credit-constrained equilibrium arises, in which both constrained and unconstrained agents engage in production. This is the only equilibrium considered in Kiyotaki. The second equilibrium type occurs with larger values of the parameter and, in this case, productive agents use all the available assets in the economy but remain credit constrained when choosing their input purchases. Finally, the third equilibrium type occurs with yet larger values of the parameter and corresponds to the case in which the borrowing constraint is not binding for any agent and, hence, productive agents choose the unconstrained input quantities.

As in the well-known model of Kiyotaki and Moore (1997), the dynamic interaction between credit limits and asset prices amplifies the magnitude and persistence of temporary productivity shocks. We find that this shock amplification first increases and then decreases with financial development. This non-monotonicity is due to financial development having two opposite effects on the income response to a negative productivity shock. First, financial development increases what we call the durable input reallocation effect by raising the leverage of productive agents. With higher leverage, more resources are reallocated between agents 
of different productivities after a technology shock. Second, financial development decreases what we call the intermediate input demand effect by reducing the downpayment required to buy the durable input. The lower the downpayment, the smaller the fall in the quantity of intermediate input used in production after the shock.

To sum up, at low levels of financial development, a fall in financial frictions increases the response of income to a negative productivity shock because it raises the magnitude of the reallocation effect, which has a first-order impact on output. At higher levels of financial development, the credit supply by unproductive agents becomes completely inelastic, which implies that productive agents use all the productive resources before and after the shock. When this is the case, the reallocation effect disappears. The effect on the intermediate input demand, on the other hand, is still present while productive agents are constrained and, thus, at higher levels of financial development, the shock amplification decreases with the fall in financial frictions.

Related literature. There is a large theoretical literature studying the mechanisms by which temporary shocks are amplified and made more persistent by the financial sector, starting with Bernanke and Gertler (1989) and Kiyotaki and Moore (1997) and continuing to this day with Gertler and Kiyotaki (2010) and Brunnermeier and Sannikov (2014), among others. We contribute to this literature by showing that the amplification of productivity shocks induced by collateral constraints is non-monotonic with respect to the tightness of this constraint.

Matsuyama (2008, 2013), Mendoza (2010), and Hirano and Yanagawa (2015) are closer to our paper because they also explore the non-monotonic effects of changes of financial frictions on aggregate quantities. Matsuyama (2008) points out that a recurring feature of models with credit market frictions is that the "properties of equilibrium often respond non-monotonically to parameter changes." Our contribution is to make these properties explicit and show the economic intuition behind them. In terms of technique we are closest to Kiyotaki and Moore (2005), which analyzes the regions of the parameter space of their model to describe the effects of financial intermediation on output and investment. A distinctive feature of our nonmonotonicity result in this setting is that it arises even when we restrict our attention to the 
regions in which productive agents are constrained. This feature contrasts with the results in Mendoza, where the non-monotonicity result arises because financial development increases amplification in a constrained equilibrium and, at the same time, decreases the likelihood of being in that constrained equilibrium economy.

Our non-monotonicity result sheds light on the mixed empirical evidence of the effects of financial development on growth and volatility. Beck, Levine and Loayza (2000) found that financial liberalization in economies with underdeveloped financial systems is usually followed by financial crises, while Jordà, Schularick and Taylor (2011) show that credit growth is a powerful predictor of economic crises. Related to this, Loayza and Rancière (2006) conclude that economic growth is positively and significantly linked to financial intermediation in the long run but negatively in the short run, especially for countries with high volatility. Easterly, Islam and Stiglitz (2001), on the other hand, finds that a higher level of development of the domestic financial sector is associated with lower volatility.

The rest of the article is organized as follows. Section 2 presents the model and analyzes the equilibrium in detail. Section 3 describes the simulation of the model and discusses the numerical results. Section 4 concludes. We leave the mathematical derivations and additional results to the online appendix.

\section{The model}

Our model is an extension of the economy with heterogeneous agents and endogenous credit constraints proposed by Kiyotaki (1998). Given their heterogeneity in productivity, agents engage in borrowing and lending. This activity has a friction in the form of an endogenous borrowing constraint, since lenders demand collateral because of the imperfect enforcement of debt contracts. We introduce a parameter multiplying the value of the collateral, which we interpret as a reduced form summary of potential factors easing or constraining the borrowing and lending between agents. We call this parameter the degree of financial development. ${ }^{1}$ 


\subsection{Model details}

In the economy, there is a continuum of infinitely-lived agents who have logarithmic preferences over the consumption good and discount the future at the rate $\beta$. Agents produce the final good with the following technoogy:

$$
y_{t}^{i} \equiv A_{t-1}^{i}\left(\frac{k_{t-1}^{i}}{\sigma}\right)^{\sigma}\left(\frac{x_{t-1}^{i}}{1-\sigma}\right)^{1-\sigma}, 0<\sigma<1
$$

where the productivity of agent $i$ in period $t, A_{t-1}^{i}$, is equal to $\alpha$ if $i$ is productive and to $\gamma$ if $i$ is unproductive. The variable $k_{t-1}^{i}$ denotes the durable input used by agent $i$ in period $t$ and $x_{t-1}^{i}$ the intermediate input. Both inputs are chosen one period in advance. The durable input is in fixed supply and does not depreciate, while the intermediate input fully depreciates every period. The durable input plays a dual role, as factor of production as well as collateral for loans.

Agent's type shifts stochastically between two states, the productive and the unproductive, according to the following Markov process: productive agents become unproductive in the next period with probability $\delta$, and unproductive agents become productive with probability $n \delta$, where $n<1$. Agents maximize their expected utility subject to the production technology and the budget constraint $c_{t}+x_{t}+q_{t}\left(k_{t}-k_{t-1}\right)=y_{t}+\frac{b_{t+1}}{r_{t}}-b_{t}$, where $c_{t}$ denotes consumption, $q_{t}$ the price of the durable input, $b_{t}$ the debt repayment, $b_{t+1}$ the new debt, and $r_{t}$ the gross interest rate. At the same time, every period, agents face the borrowing constraint

$$
b_{t+1} \leq \theta q_{t+1} k_{t}, \theta \in[0, \infty)
$$

which says that the debt repayment cannot exceed the adjusted value of the collateral at period $t+1$. The parameter $\theta$ is a measure of the fraction of collateral that lenders can recover. $^{2}$

\subsection{Equilibrium types}

An equilibrium of this economy is defined in the standard way: a sequence of allocations 
for each type of agent $\left\{\left[c_{t}, k_{t}, x_{t}, b_{t}\right]_{\forall i}\right\}_{t=0}^{\infty}$ and prices $\left\{q_{t}, r_{t}\right\}_{t=0}^{\infty}$ such that i) agents maximize their lifetime expected utility and ii) durable input, final good, and credit markets clear, i.e., $\int_{i \in U}\left(c_{t}^{i}+x_{t}^{i}\right) d i+\int_{i \in P}\left(c_{t}^{i}+x_{t}^{i}\right) d i=\int_{i \in U} y_{t}^{i} d i+\int_{i \in P} y_{t}^{i} d i, \int_{i \in U} k_{t-1}^{i} d i+\int_{i \in P} k_{t-1}^{i} d i=1$, and $\int_{i \in U} b_{t}^{i} d i+\int_{i \in P} b_{t}^{i} d i=0$, where $U$ denotes the set of unproductive agents and $P$ the set of productive ones. There are three types of unique equilibria in our model, each corresponding to a region of the parameter space of $\theta$.

\subsubsection{Equilibrium Type I: Constrained Productive Agents}

Equilibrium type $I$ occurs when the borrowing constraint is binding for productive agents and all agents in the economy engage in production. In each period, both productive and unproductive agents optimally chose to consume a fraction $(1-\beta)$ of their wealth $w_{t}$, defined as $w_{t}^{i} \equiv y_{t}^{i}+q_{t} k_{t-1}^{i}-b_{t}^{i}$.

Unproductive agents. The optimal intermediate-to-durable input ratio of unproductive agents is given by $\frac{x_{t}^{i}}{k_{t}^{i}}=\frac{1-\sigma}{\sigma} u_{t}$, where $u_{t} \equiv q_{t}-q_{t+1} / r_{t}$ is defined as the user cost of the durable input. The real interest rate is equal to the rate of return of unproductive agents, i.e. $r_{t}=\gamma u_{t}^{-\sigma}$ when they engage in production. Intuitively, since in this equilibrium type unproductive agents use their savings to lend and to produce, both rates of return must be the same.

Productive agents. The optimal intermediate-to-durable input ratio of productive

agents, $\frac{x_{t}^{i}}{k_{t}^{i}} \equiv g_{t}$, depends positively both on the durable input user cost $u_{t}$ and, when $\theta<1$, on the opportunity cost of the downpayment:

$$
\frac{\sigma}{1-\sigma} g_{t}=u_{t}+(1-\theta) \frac{q_{t+1}}{r_{t}}\left(\frac{h_{t}-r_{t}}{h_{t}}\right)
$$

where $h_{t} \equiv \frac{\partial y_{t+1}}{\partial x_{t}}=\alpha\left(\frac{\sigma}{1-\sigma} g_{t}\right)^{-\sigma}$ is the rate of return of productive agents, i.e. the marginal product of the intermediate input. This rate of return exceeds the interest rate and, therefore, productive agents borrow up to the credit limit. 


\subsubsection{Equilibrium Type $I I$ : No Production by Unproductive Agents}

The second type of equilibrium, which we call type $I I$, is one in which the borrowing constraint is still binding for productive agents but unproductive agents lend all their savings and, thus, produce nothing. The equilibrium type $I I$ differs from type $I$ in that productive agents end up holding all the inputs in the economy.

To understand this equilibrium type better, it is useful to look at the credit market clearing

condition, $-\int_{i \in U} b_{t}^{i} d i=\int_{i \in P} b_{t}^{i} d i$, together with the unproductive agents' budget constraint. This determines the amount of durable input held by unproductive agents when the equilibrium type is $I$ or $I I$ :

$$
\left(q_{t}+\frac{1-\sigma}{\sigma}\right) \int_{i \in U} k_{t}^{i}=\beta\left(1-s_{t}\right) W_{t}-\int_{i \in P} \frac{\theta q_{t+1} k_{t}^{i}}{r_{t}} d i
$$

where $W_{t}$ denotes aggregate wealth and $s_{t}$ the wealth share of productive agents. Condition (3) determines whether a type $I$ or type $I I$ equilibrium holds: if the right hand side is positive when the interest rate is the type $I$ interest rate, then equilibrium $I$ prevails. If this is not the case, then the equilibrium type is $I I$ : productive agents hold all the durable input and the interest rate is equal to $r_{t}=\frac{\theta q_{t+1}}{\beta\left(1-s_{t}\right) W_{t}} \cdot{ }^{3}$

Figure 1 shows graphically the interest rate that equalizes the demand and supply of credit for different values of $\theta$. The supply of funds by unproductive agents is completely elastic at $\gamma u_{t}^{-\sigma}$ but it cannot be higher than their after-consumption wealth. The demand for funds by productive agents, on the other hand, is completely elastic at $\alpha u_{t}^{-\sigma}$ but, since they are credit constrained, it cannot be higher than $\theta \frac{q_{t+1}}{r_{t}}{ }^{4}$

\subsubsection{Equilibrium Type III: Unconstrained Productive Agents}

The third equilibrium type, which we call type $I I I$, occurs when the borrowing constraint of productive agents is not binding. Unconstrained productive agents keep on borrowing and acquiring production inputs as long as the interest rate is lower than their rate of return. This equilibrium, thus, requires that the interest rate is equal to the rate of return of productive agents and that productive agents are willing to hold all the durable input in the economy. 
The optimal input ratio for productive agents in this equilibrium type is the unconstrained

one, $\frac{x_{t}}{k_{t}}=\frac{1-\sigma}{\sigma} u_{t}$, and the interest rate now reflects the marginal product of the intermediate input for productive agents, i.e. $r_{t}=\alpha u_{t}^{-\sigma}$.

\section{Numerical Example}

We now simulate the model to study the transition dynamics after an unexpected negative aggregate productivity shock and evaluate them for different levels of financial development. Under the parameter values chosen, the range $\theta \in[0.75,1.1]$ covers the three equilibrium types. In Kiyotaki (1998) the financial efficiency parameter $\theta$ is equal to one. The author then makes the necessary assumptions about the other parameter values to ensure the equilibrium is of the first type.

\subsection{Steady state}

Given the logarithmic preferences and the linearity of the production functions, the equilibrium of this economy can be described in terms of the aggregate wealth, $W_{t}$, the productive agents wealth share, $s_{t}$, the durable input price, $q_{t}$, and the durable input user cost, $u_{t}$. When $\left(W_{t+1}, s_{t+1}, q_{t+1}, u_{t+1}\right)=\left(W_{t}, s_{t}, q_{t}, u_{t}\right)$, the economy is in a steady state. Figure 2 shows how the steady-state level of some of these variables changes with the level of financial development. In what follows we stress three results.

First, in equilibrium types $I$ and $I I$, the steady-state total ouptut increases with financial development. Financial development improves the allocation efficiency of the economy by increasing the fraction of resources used by productive agents and, as a consequence, output increases.

Second, the optimal ratio of intermediate to durable input for constrained agents (i.e. productive agents in equilibria $I$ and $I I)$ is always larger than the the same ratio for unconstratined agents, but the difference between the two ratios is decreasing in $\theta$. This result implies that the opportunity cost of the downpayment in equation (2) is positive and decreasing with financial development. 
Third, financial development increases the demand and the price $q$ of the durable input. By decreasing the opportunity cost of the downpayment and the actual downpayment, financial development reduces productive agents' cost of acquiring the durable input. In addition, financial development raises the wealth of productive and unproductive agents because it increases the steady-state output. It follows that both agent types increase their demand for the durable input and, hence, its price $q$ also increases. The third plot in Figure 2 illustrates this point.

\section{$3.2 \quad$ Dynamics}

We next explore the dynamics of the main variables after a $1 \%$ unexpected and temporary negative shock to aggregate productivity. The magnitude of the shock and the values of $\theta$ considered guarantee that the equilibrium type at every point in the transition is the same as the one in steady state. ${ }^{5}$

Figure 3 shows the percentage deviation of output from steady state due to the productivity shock for different values of $\theta$. The evolution of output is almost identical for the two extreme values of $\theta$ considered, $\theta=0.75$ and $\theta=1$, while it reacts more for intermediate values of $\theta$. The relationship between financial development and the shock amplification is nonmonotonic: when the equilibrium type is $I$, the deviation of output from steady state increases with financial development; it drops significantly when the equilibrium type becomes $I I$, and decreases with financial development while the equilibrium type is $I I$; once we reach equilibrium type $I I I$, the deviation of output no longer depends on $\theta$.

The pattern of this path is almost identical for the deviation of aggregate consumption, aggregate wealth and the durable input relative price. It is also very similar to the paths of the productive agents wealth share, the intermediate input purchases and total borrowings. The online appendix contains the plots of all these variables.

\subsection{Decomposition of the total effect on output}

In the analysis that follows we explain why the reaction of output to a shock changes non-monotonically with financial development. We start the analysis by tracing the reaction 
of output to changes in the quantity of durable and intermediate inputs used in production (section 3.3). We then discuss the main drivers of the changes in the inputs and determine how financial development affects them (section 3.4). Our analysis shows that the non-monotonic reaction of output to a shock arises from financial development changing the leverage of productive agents, the cost of the durable input, and the behavior of the credit market.

We first decompose the change in output after a shock into changes in the intermediate and durable inputs. In any equilibrium type, total output is equal to output by productive agents plus output by unproductive agents. Hence, in steady state, $Y^{S S}=\alpha \frac{\left(g^{S S}\right)^{1-\sigma}}{\sigma^{\sigma}(1-\sigma)^{1-\sigma}} K_{P}^{S S}+$ $\gamma \frac{\left(\frac{1-\sigma}{\sigma} u^{S S}\right)^{1-\sigma}}{\sigma^{\sigma}(1-\sigma)^{1-\sigma}}\left(1-K_{P}^{S S}\right)$, where $g^{S S}$ is defined in equation (2) and $K_{P}^{S S}$ denotes the amount of durable input owned by productive agents in steady state.

By totally differentiating output with respect to the percentage change in productivity $\Delta$ one period after the shock, we find that the elasticity of output is the sum of two effects - the durable input reallocation effect and the intermediate input demand effect:

$$
\frac{d \ln Y}{d \triangle}=\underbrace{\rho^{S S \frac{d \ln K_{p}}{d \triangle}}}_{\text {Reallocation effect }}+\underbrace{\psi^{S S}\left((1-\sigma) \frac{d \ln g}{d \triangle}\right)+1-\psi^{S S}\left((1-\sigma) \frac{d \ln u}{d \triangle}\right)}_{\text {Intermediate input demand effect }} .
$$

The first term in equation (4) measures how much output is lost or gained due to the reallocation of the durable input from productive to unproductive agents. This term is the product of the quantity of durable input that moves between agents, $\frac{d \ln K_{p}}{d \triangle}$, and the difference in the marginal product of productive and unproductive agents, $\rho^{S S}$. The second term of equation (4) is the impact on output of changes in the relative use of the intermediate input after the shock. This term is a weighted average of the change in the relative use of the intermediate input by productive and unproductive agents, with the weights $\psi^{S S}$ and $\left(1-\psi^{S S}\right)$ being their respective share of the steady-state output.

The plots of Figure 4 show that the combination of the reallocation and intermediate input effects generate the non-monotonic impact of financial development on the reaction of output to a shock. In particular, in a type $I$ equilibrium, the reallocation of the durable input between agents has a first-order effect on output. Since this reallocation increases with 
financial development, so does the reaction of output to the shock. Once the equilibrium is in regions $I I$ and $I I I$, the reallocation effect disappears, and only the intermediate input effect persists. Since this effect decreases with financial development, so does the reaction of output to the shock. ${ }^{6}$ In the next section we explore the drivers of the behavior of the reallocation and intermediate input effects.

\subsection{Results analysis}

In this subsection we firstly examine why the reallocation effect increases with financial development; secondly, why the intermediate input effect decreases with financial development in regions $I$ and $I I$, and, thirdly, why the former dominates over the latter.

The reallocation effect increases with financial development. Following a negative technology shock, productive agents' wealth falls relatively more than the wealth of unproductive agents. This is called the balance sheet effect and it increases with financial development because of the rise in productive agents' borrowings. When the equilibrium type is $I$, it leads to a reallocation of the durable input from productive to unproductive agents, which is now used less efficiently. As a consequence, output falls. The first plot in Figure 5 shows that this direct effect of the shock on $K_{P}$ is increasing with $\theta$ in regions $I$ and $I I$.

But, in a type $I$ equilibrium, the effect on $K_{p}$ does not stop here. The future price of the durable input decreases after the negative technology shock. As a consequence, the credit constraint tightens, productive agents demand less durable input, and the reallocation effect is magnified. The second plot in Figure 5 shows this. The effect of the durable input price becomes a more significant part of the total reallocation effect as $\theta$ increases, since changes in $q_{t+1}$ have a larger impact on the credit constraint when financial intermediation is high. The reallocation effect, while active, has a first-order impact on output because it implies transferring inputs from more productive to less productive. ${ }^{7}$ The intermediate input effect, on the other hand, is just about each agent fine tuning the mix of inputs used in production.

\section{The intermediate input demand effect decreases with financial development.} The intermediate input effect is driven by productive and unproductive agents changing the

optimal mix of inputs used in production after a shock. The elasticities $\frac{d \ln g}{d \triangle}$ and $\frac{d \ln u}{d \triangle}$ in 
equation (4) measure these changes and both elasticities decrease with financial development under equilibrium types $I$ and $I I$. This is because, ultimately, financial development increases the elasticity of the durable input to its user cost (region $I I$ ) and amplifies the fall in credit after a negative shock (region $I$ ). These elasticities are shown in the third and fourth plot of Figure 5 .

Focusing first in region $I I$, when a negative productivity shock hits the economy the durable input demand falls. To clear the market, the user cost $u_{t}$ must decrease and, hence, the elasticity $\frac{d \ln u}{d \triangle}$ is positive. Financial development reduces this elasticity since, by decreasing the downpayment $(1-\theta) \frac{q_{t+1}}{r_{t}}$ and its cost, it makes the durable input demand more sensitive to the user cost $u_{t}$. A smaller change in $u_{t}$ is thus necessary to clear the market, and so the elasticity $\frac{d \ln u}{d \triangle}$ falls with $\theta$. In addition, financial development reduces the increase in the downpayment's opportunity cost, $(1-\theta) \frac{q_{t+1}}{r_{t}}\left(1-\frac{r_{t}}{h_{t}}\right)$, and thus the elasticity $\frac{d \ln g}{d \triangle}$ also falls unambiguously with $\theta$ (see equation 2).

In region $\mathrm{I}$, the change in the aggregate demand of the durable input after a shock is ambiguous. In addition to the effects present in region $I I$, a negative productivity shock decreases tomorrow's durable input price, $\frac{q_{t+1}}{r_{t}}$, because $r_{t}$ is now inelastic (see Figure 1). ${ }^{8}$ On this account, the borrowing constraint tightens and total credit falls. The fall in credit has a positive effect on the durable input aggregate demand because unproductive agents use this input more intensively (see the second plot in Figure 2). If this was the only effect after a shock, the user cost would have to increase to clear the market. Once we consider all the effects that are also present in region II, the change in the aggregate demand of land is ambiguous, and therefore the elasticity $\frac{d \ln u}{d \triangle}$ can be positive or negative. The negative relationship between $\frac{d \ln u}{d \triangle}$ and $\theta$, however, is not ambiguous. Specifically, since financial development increases the fall in the durable input price $\frac{q_{t+1}}{r_{t}}$, the elasticity $\frac{d \ln u}{d \triangle}$ must decrease with financial development. This implies that the elasticity $\frac{d \ln g}{d \triangle}$ also falls with $\theta$.

It remains to explain why there is a jump in the intermediate input demand effect between regions $I$ and $I I$. This jump is due to the productivity shock having no effect on the discounted durable input price $\frac{q_{t+1}}{r_{t}}$ in region $I I$. In this region, unproductive agents lend all their resources irrespective of the interest rate $r_{t}$, and so the supply of credit is perfectly inelastic (see Figure 
1). Changes in the demand of credit after a shock, i.e. changes in $q_{t+1}$, are almost offset by the price of credit $r_{t} \cdot{ }^{9}$ Consequently, in region $I I$, there is a larger fall in the user cost.

\section{Concluding remarks}

We extend the model of Kiyotaki (1998) to analyze the relationship between financial development and the amplification of technological shocks. Financial intermediation amplifies the technological component of business cycle fluctuations through the effects on the prices of the collateral and the relative wealth of borrowers, as in the traditional models of endogenous collateral constraints. Our contribution is to show that this amplification behaves non-monotonically with financial development and that there is an intermediate size of the financial sector which leads to the highest amplification.

We illustrate that this result is due to the relationship between financial development and the effects of the productivity shock on the input purchases of each type of agents and, more importantly, on the input reallocation across types of producers. While the former has a negative relationship with the level of financial development because of the fall in the downpayment cost, the latter, when active, has a positive relationship with the level of financial development because of the rise in the leverage of productive agents.

In a richer setup with a continuum of productivity types, the response of income to a shock could also be non-monotonic. For each level of financial development a productivity cutoff would determine the set of agents active in production. A negative shock would lower the cutoff level and persistently reduce the average productivity along the path to the steadystate. The shock amplification would then depend on the magnitude of the changes in average

productivity which, in turn, would depend on the density of the productivity distribution at the equilibrium cutoff. 


\section{References}

Beck, Thorsten, Ross Levine and Norman V. Loayza (2000) "Finance and the sources of growth." Journal of Financial Economics 58, 195-209.

Bernanke, Ben and Mark Gertler (1989) "Agency Costs, Net Worth, and Business Fluctuations." American Economic Review 79, 14-31.

Brunnermeier, Markus K. and Yuliy Sannikov (2014) "A macroeconomic model with a financial sector." The American Economic Review 104, 379-421.

Easterly, William, Roumeen Islam and Joseph Stiglitz (2001) "Shaken and Stirred: Explaining Growth Volatility." In Boris Pleskovic and Nicholas Stern, editors, "Annual World Bank Conference on Development Economics," .

Gertler, Mark and Nobuhiro Kiyotaki (2010) "Chapter 11 - Financial Intermediation and Credit Policy in Business Cycle Analysis." volume 3 of Handbook of Monetary Economics. Elsevier, pp. $547-599$.

Hirano, Tomohiro and Noriyuki Yanagawa (2015) "Asset Bubbles, Endogenous Growth, and Financial Frictions." Working paper, The University of Tokyo.

Jordà, Òscar, Moritz Schularick and Alan M Taylor (2011) "Financial crises, credit booms, and external imbalances: 140 years of lessons." IMF Economic Review 59, 340-378.

Kiyotaki, Nobuhiro (1998) "Credit and Business Cycles." The Japanese Economic Review 49, $18-35$.

Kiyotaki, Nobuhiro and John Moore (1997) "Credit Cycles." Journal of Political Economy $105,211-248$.

Kiyotaki, Nobuhiro and John Moore (2005) "Financial deepening." Journal of the European Economic Association 3, 701-713.

Loayza, Norman V. and Romain Rancière (2006) "Financial development, financial fragility, and growth." Journal of Money, Credit and Banking , 1051-1076. 
Matsuyama, Kiminori (2008) "Aggregate implications of credit market imperfections." In “NBER Macroeconomics Annual 2007, Volume 22," University of Chicago Press, pp. 1-60.

Matsuyama, Kiminori (2013) "The Good, the Bad, and the Ugly: An inquiry into the causes and nature of credit cycles." Theoretical Economics 8, 623-651.

Mendoza, Enrique G. (2010) "Sudden Stops, Financial Crises, and Leverage." The American Economic Review 100, 1941-1966. 


\section{Notes}

1. The details of the model are described in the online Appendix.

2. In the numerical section, we look at values of $\theta$ below and above 1 , but all the relevant effects of financial development take place for values smaller than 1. Empirically, the value of $\theta$ measured as the value of capital structures over credit is smaller than one for most countries; in the case of the United States, it is equal to 0.98 (data source: U.S. Bureau of Economic Analysis).

3. Provided that this interest rate is below the productive agents rate of return $\alpha u_{t}^{-\sigma}$, productive agents would like to borrow more so they are indeed constrained.

4. For simplicity, we plot the credit demand and supply as if all the variables except the interest rate were independent of $\theta$, even though this is not the case in equilibrium.

5. The main results do not change when we consider values for $\theta$ such that the equilibrium type along the dynamics differ from the steady-state equilibrium type but the analysis becomes more involved.

6. It is worth noting that the the reallocation effect is sufficient to generate a non-monotonic change in the reaction of output. Shock amplification is zero when there is no financial intermediation and also when credit constraints do not bind.

7. Given that it has a first-order impact on output, the reallocation effect is the main mechanism behind the result in Kiyotaki (1998).

8. Strictly speaking, in region I the aggregate demand of durable input also depends on the unproductive agents' demand, which moves in the opposite direction than the productive agents' demand.

9. For the sake of accuracy, the ratio $\frac{q_{t+1}}{r_{t}}$ does change in region II but by a small amount. In addition to reacting to changes in $q_{t+1}$, the interest rate $r_{t}$ is also affected by changes in the wealth of unproductive agents. These changes are small and decrease with financial development. 


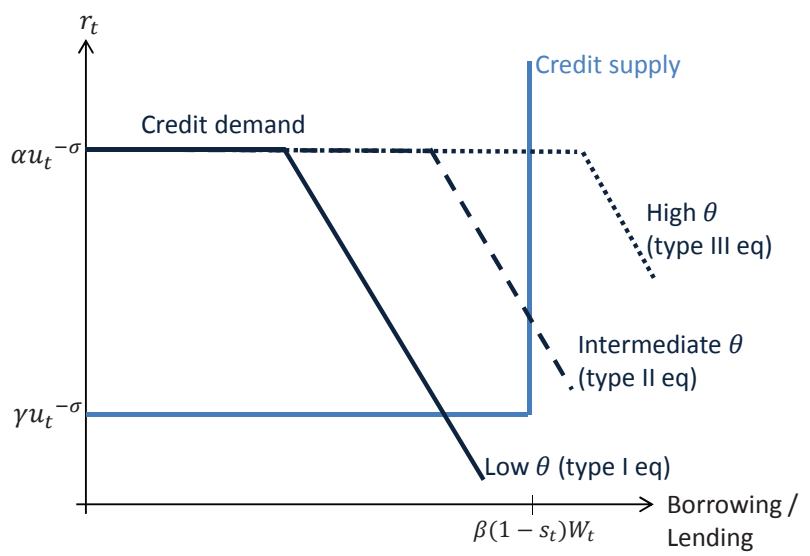

Figure 1: Credit market equilibrium. 

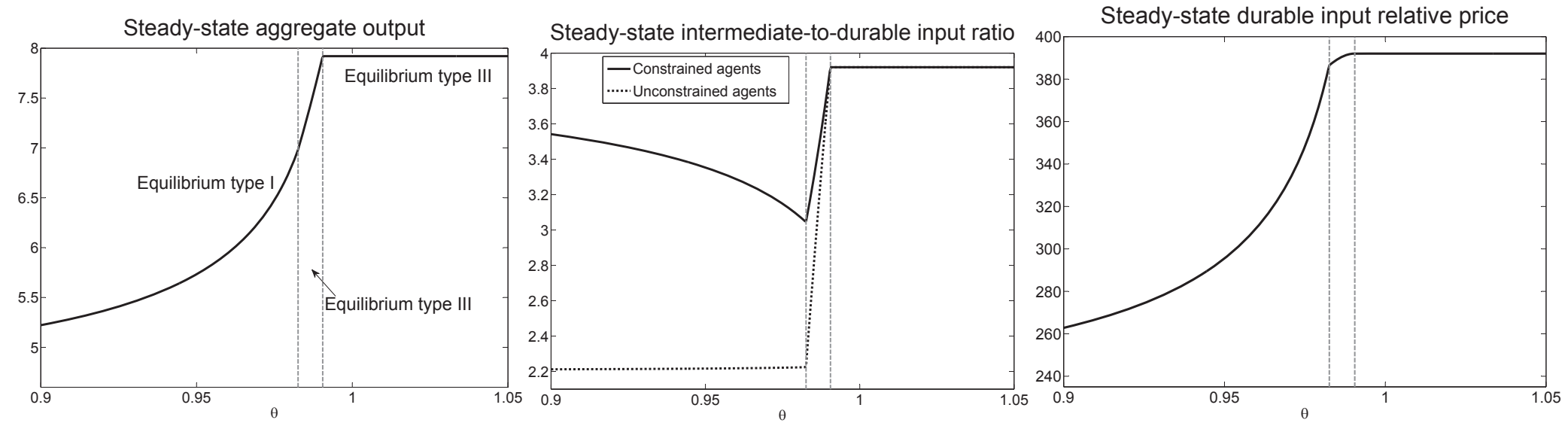

Figure 2: Steady-state output, input ratio and durable input price as a function of $\theta$. 
Aggregate output - deviation from SS (in \%) Average absolute deviation of output from SS
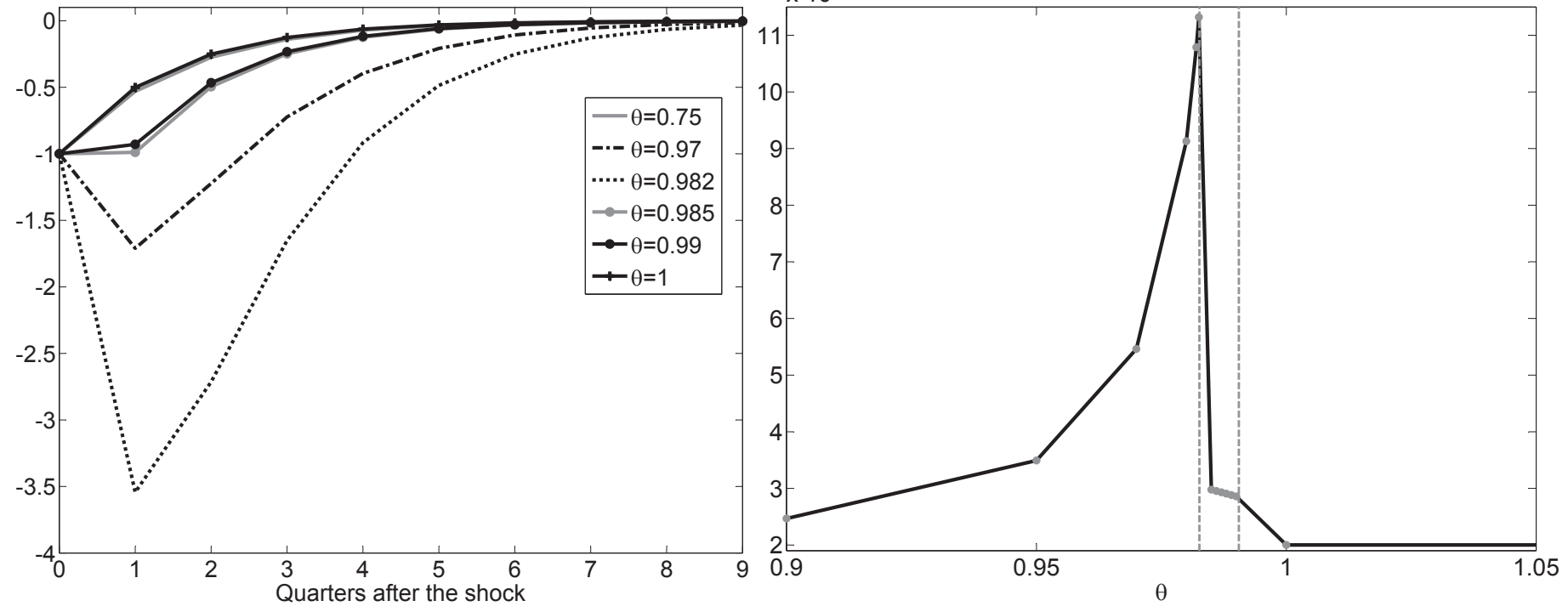

Figure 3: Effect of financial development on shock amplification. 

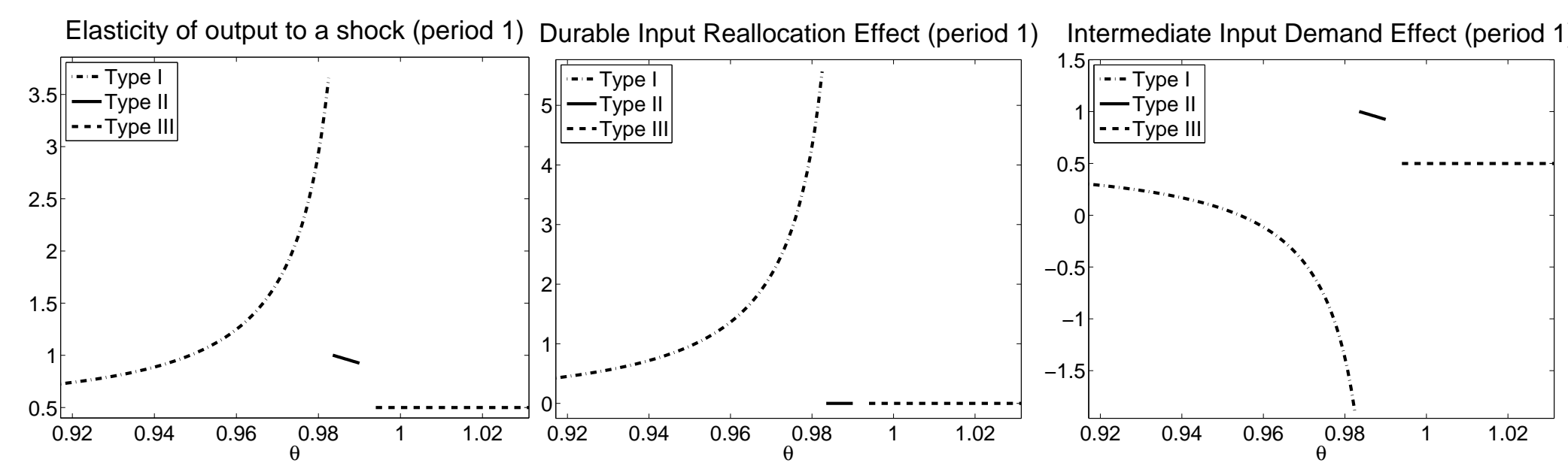

Figure 4: Decomposition of the total output elasticity to technology shocks. 


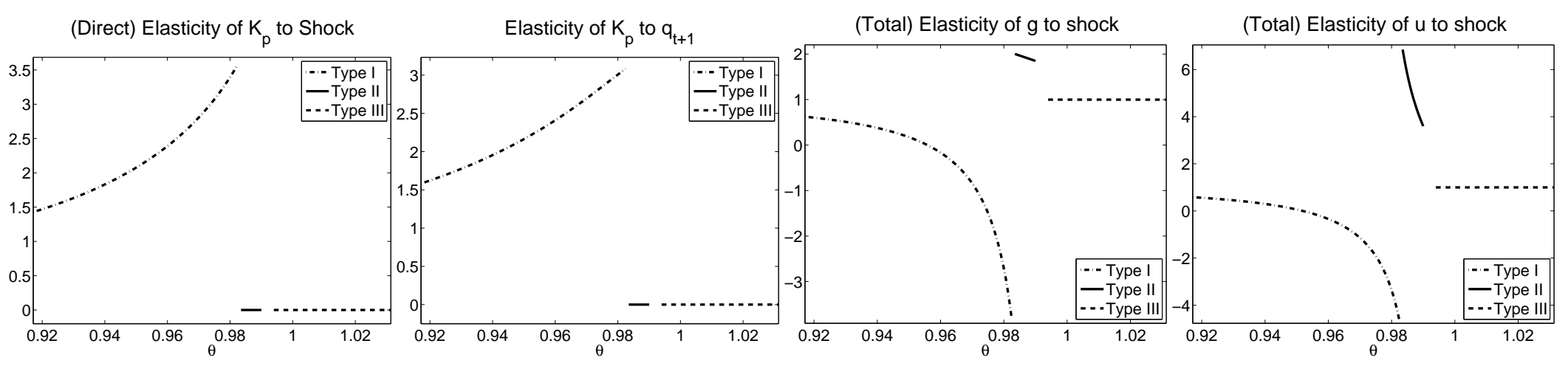

Figure 5: Financial development and inputs' elasticities (first period) 